\title{
Opinion
}

\section{More Significant Life for Diabetic Patients in the Perspectives of Anti-Aging}

\author{
Hiroshi Bando, MD, PhD, FACP* \\ Tokushima University and Medical Research, Nakashowa I-6I, Tokushima 770-0943, Japan
}

*Corresponding author

Hiroshi Bando, MD, PhD, FACP

Instructor, Tokushima University and Medical Research, Nakashowa I-6I, Tokushima 770-0943, Japan; Tel. +8I-90-3I87-2485; Fax: +8I-88-603-I030;

E-mail: pianomed@bronze.ocn.ne.jp

Article information

Received: July 26 $6^{\text {th }}$, 2018; Accepted: July $27^{\text {th }}$, 2018; Published: July $27^{\text {th }}, 2018$

\section{Cite this article}

Bando H. More significant life for diabetic patients in the perspectives of anti-aging. Diabetes Res Open J. 2018; 4(I): 9-II. doi: I0.17/40/DROJ-4-I37

For the patients with diabetes, basal daily lifestyle would be considered in the light of meal, exercise, rest, alcohol intake, smoking and oral health. These six factors are from the concept as a basic direction of "Health Japan 21" for comprehensive implementation of national health promotion. ${ }^{1}$ Satisfactory control of lifestyle can lead to protection and treatment of diabetes and successful anti-aging. From this implication, to check up physical and mental condition would be important and helpful in clinical practice.

Concerning Anti-Aging Medicine (AAM), Kahn and Rowe formerly initiated in 1980-90's, proposing successful aging. After that, AAM has been developed in the world for decades until today. ${ }^{2,3}$ Currently, clinical importance of AAM includes not only to maintain healthy condition and to protect diseases, but also to promote activities of daily living (ADL) and quality of life (QOL), leading to long and significant lives. ${ }^{4}$ Furthermore, adequate judgement and development of AAM would be also considered in the light of medical, social, economical, and ethical aspects. ${ }^{5}$

In order to obtain optimal daily life, the status of QOL and ADL have to be evaluated by adequate method. As for AAM, several aspects would be necessary to evaluate, such as dietary and exercise habit, nutrition, physical activity, resting, alcohol, smoking and dental health. These factors are pointed out for national health promotion by the Ministry of Heath, Labour and Welfare of Japan. ${ }^{6}$ It has been known as the "National Health Promotion Movement in the $21^{\text {st }}$ Century (Health Japan 21)" as the third health promotion measure for citizens since 2000.

A variety of questionnaires for QOL were proposed until today for years. One of the famous questionnaire would be short form-36 (SF-36), including international version and also Japanese version. ${ }^{7}$ In addition, there were several questionnaire about QOL, including World health Organization (WHO)/QOL-26, WHO-5 Well-Being Index, cognitive function and five-level version of the EuroQol five-dimensional questionnaire. ${ }^{8-11}$ Indeed, these questionnaires have showed meaningful method and result, but rather complicated tendency were observed. Compared to these, AntiAging QOL Common Questionnaire (AAQOL) seems to be useful for its convenience taking only about a few minutes.

The AAQOL consists of more than 50 items of physical and mental symptoms, and six lifestyle items. For each question, subjects can answer in simple way by 5 -point scale (1. None, 2. Little, 3. Mild, 4. Moderate, 5. Severe). ${ }^{12}$

Regarding the studies for AAQOL, authors have continued various analyses for years. Formerly, each item in AAQOL was statistically calculated for investigation. Authors have proposed new method for analysis. Its way is to categorize several items into one group with totally several categorization. ${ }^{13}$ After some trials, we proposed exam method for 8 categories with 7 physical and mental items each.

Taking this method into consideration, we investigated subjects and patients with various situations and diseases. They included patients with chronic renal failure and hemodialysis, subjects with masters athletes in ice-skating and athletics. ${ }^{14,15}$

There were several impressive data to mention from the 
results concerning masters athletes. Their exercise habits seemed to be stable, which was mostly 3-4 days a week constantly throughout the year. As to the lifestyle, too much eating is rare, the frequency of drinking is rather high, but the amount of drinking is low, and opportunity of communicate to others is frequent. When age and gender were matched and compared with the control group, masters athletes showed significantly lower physical and psychological symptoms.

From these way of living and lifestyle, masters athletes suggested to have positive and happier life. ${ }^{14,15}$ Thus, application of AAQOL to various clinical research studies would be useful and expected to obtain the meaningful results of mutual relationship in the light of physical, mental, and social aspects.

Concerning the circumstances at the birth of AAQOL, medical care situation was deeply affected at that time. It was just when AAM was introduced to Japan from United States, when expectations and needs for AAM was recognized in medical field. Under such circumstances, debates on the influence of aging for various symptoms were accumulated.

As a result, researches focusing on the health surveillance form of the items were developed reflecting health condition of people with $20-80$ years old. ${ }^{16}$ Specifically, symptoms are roughly divided into two categories which are physical symptoms and psychological symptoms, as well as lifestyle habits. AAQOL includes not only items from medicine and health, but also items from social aspect, in which items and features are commonly used for research in occupational hygiene. ${ }^{17}$

The beneficial point of AAQOL has been simple, convenient and useful. Therefore, AAQOL has been used for clinical practice, clinical research study, and also medical and/or health checkup for usual people. It has been developed which has been performed and developed widely for long years in Japan. Especially, AAM medical and health checkup is called in Human Dock in Japan. It can focus on evaluating degree of impaired function in any organ system by utilizing AAQOL Questionnaire. ${ }^{18}$

Continuous development includes the further research of AAQOL for its usefulness and effectiveness which are from much data in thousands of subjects. ${ }^{18,19}$

Recently, AAQOL Questionnaire itself was studied in detail. Using AAQOL, lifestyles and functional ages, more than 6000 cases were investigated. The correlations of 5 age factors (muscle, bone, hormone, nerve, blood vessel) and 10 symptoms were investigated. ${ }^{19}$ Ten symptoms include 5 physical factors (ocular symptoms, palpitations/shortness of breath, gastrointestinal problems, stiffness, weight problems) and 5 mental factors (depression, mental anxiety, mental confusion, insomnia and emotional anxiety). As the results, detail influencing correlations were found 4 factors with lifestyle, 5 factors with body, and 5 factors with mind. ${ }^{19}$

Furthermore, the results showed the validity of the
AAQOL Questionnaire and some points recommended to modify. Regarding the future direction, to select adequate items into focus and to compare with other QOL rating scales would be continued for further investigation. Regarding to managing and handing the health status QOL scores, it would be necessary to collect much data from enough number of samples, and to develop fair and highly transparent discussion involving a large number of medical and health researchers.

In summary, clinical significance of AAQOL for AAM have been described in this article. It is convenient and useful for clinical practice and research, as well as health and medical checkup in various situations. ${ }^{20}$ Moreover, AAQOL is beneficial for other area, such as cosmetics, food and medicine, exercise and sports, and health industry. As AAM is developing in broader fields, AAQOL is expected to be applied to further extent in a variety of occasion, leading to successful aging. Furthermore, successful aging will provide more significant and meaningful life to the diabetic patients.

\section{REFERENCES}

1. The Ministry of Health, Labour and Welfare, Japan. Health Japan 21. A Basic Direction for Comprehensive Implementation of National Health Promotion, 2013. https://www.mhlw.go.jp/ file/06-Seisakujouhou-10900000-Kenkoukyoku/0000047330. pdf

2. Kahn RL. On "Successful aging and well-being: self-rated compared with Rowe and Kahn”. Gerontologist. 2002; 42(6): 725-726.

3. Rowe JW, Kahn RL. Successful aging 2.0: Conceptual expansions for the 21 st century. J Gerontol B Psychol Sci Soc Sci. 2015; 70(4): 593-596. doi: 10.1093/geronb/gbv025

4. Martin P, Kelly N, Kahana B, et al. Defining successful aging: A tangible or elusive concept? Gerontologist. 2015; 55(1): 14-25. doi: 10.1093/geront/gnu044

5. Whitley E, Benzeval M, Popham F. Associations of successful aging with socioeconomic position across the life-course. I Aging Health. 2016; 898264316665208. doi: 10.1177/0898264316665208

6. The Ministry of Health, Labour and Welfare, Japan. Measures against Lifestyle-Related Diseases through "Health Japan 21" and Promotion of "Shokuiku (food and nutrition education)", 2008. https://www.mhlw.go.jp/english/wp/wp-hw2/part2/p2c1s3.pdf

7. Fukuhara S, Ware JE Jr, Kosinski M, Wada S, Gandek B. Psychometric and clinical tests of validity of the Japanese SF-36 Health Survey. J Clin Epidemiol. 1998; 51: 1045-1053.

8. Pace-Schott EF, Spencer RM. Age-related changes in the cognitive function of sleep. Prog Brain Res. 2011; 191: 75-89.

9. Ikeda S, Shiroiwa T, Igarashi A. Developing a Japanese version 
of the EQ-5D-5L value set. J Natl Inst Public Health. 2015; 64: $47-$ 55 .

10. Topp CW, Østergaard SD, Søndergaard S, Bech P. The WHO-5 Well-Being Index: A systematic review of the literature. Psychother Psychosom. 2015; 84(3): 167-176. doi: 10.1159/000376585

11. Shiroiwa T, Ikeda S, Noto S, et al. Comparison of value set based on DCE and/or TTO data: Scoring for EQ-5D-5L Health States in Japan. Value Health. 2016; 19(5): 648-654. doi: 10.1016/j. jval.2016.03.1834

12. Yonei Y, Takahashi Y, Watanabe M, et al. Effects on the human body of a dietary supplement containing l-carnitine and Garcinia cambogia extract: A study using double-blind tests. J Clin Biochem Nutr. 2008; 42: 89-103.

13. Bando H, Yoshioka T, Yonei Y, Nakamura T. Investigation of quality life in athletes from an anti-aging perspective. Primary Care Japan. 2006; 4(1): 47-51.

14. Bando H, Takenaka Y, Nakamura T, Kounoike K, Yonei Y. Investigation for Quality of Life (QOL) and self-esteem for health in masters' athletes. Glycative Stress Research. 2015; 2 (4): 174-181. doi: 10.24659/gsr.2.4_174
15. Bando H, Nakamura T, Yonei Y, Takenaka Y, Seki K. Lipid profile of masters athletes in ice-skating, a model of anti-aging research. Glycative Stress Research. 2015; 2(2):52-57. doi: 10.24659/ gsr.2.2_052

16. Yonei Y, Mizuno Y, Orimo H, et al. Effect of eletro-potential therapy on symptoms associated with QOL and aging. Anti-Aging Medicine. 2003; 2: 16-23.

17. Uno B. Effective utilization of questionnaires in regular medical checkups. Occupational Health Management (Rodo Eisei Kanri) [in Japanese]. 2001; 12: 45-51.

18. Yonei Y, Takabe W. Aging assessment by anti-aging medical checkup. Health Evaluation and Promotion. 2015; 42: 459-464.

19. Oguma Y, Iida K, Yonei Y, Satoh T. Significance evaluation of Anti-Aging QOL Common Questionnaire. Glycative Stress Research. 2016; 3 (3): 177-185. doi: 10.24659/gsr.3.3_177

20. Yabukita H, Miyazaki R, Nomoto K, et al. Characteristics of physical functions in elderly people requiring support. Anti-Aging Medicine. 2013; 10: 16-20. 